\title{
Successful Therapeutic Management of Hydrometra in a Doe- A Case Report
}

\author{
B. Balamurugan ${ }^{1}$, Abhishek Kumar ${ }^{1 *}$, M. Ramamoorthy ${ }^{2}$ and Ajaz Ali ${ }^{1}$ \\ ${ }^{1}$ Division of Animal Reproduction, ICAR- Indian Veterinary Research Institute, Bareilly- \\ 243122, Uttar Pradesh, India \\ *Corresponding author
}

\section{A B S T R A C T}

\begin{tabular}{|l|}
\hline Ke y w or d s \\
Non-descript doe, \\
Hydrometra, \\
$\begin{array}{l}\text { Ultrasonography } \\
\text { (USG), Vetmate }\end{array}$ \\
\hline Article Info \\
\hline $\begin{array}{l}\text { Accepted: } \\
\text { 15 June } 2018 \\
\text { Available Online: } \\
\text { 10 July } 2018\end{array}$ \\
\hline
\end{tabular}

Hydrometra is one of the causes of infertility in goats and this condition is also called as pseudo pregnancy or cloud burst. A primiparous non-descript doe aged two and half years was presented to Referral veterinary polyclinic (Veterinary Gynaecology and Obstetrics section) of the Indian Veterinary Research Institute, Izatnagar with distended abdomen and history of breeding five months back. On ventral abdominal palpation and per-vaginal examination, no any fetal structures or palpable mass was felt. All the vital parameters were within the normal range. Ultrasonographic examination revealed the presence of anechoic fluid occupying the entire uterus and fetal structures as well as placentomes were absent. The condition was diagnosed as hydrometra. Two doses of Vetmate ${ }^{\circledR}$ Inj. (Cloprostenol- Synthetic Prostaglandin $\mathrm{F}_{2} \alpha 250 \mu \mathrm{g} / \mathrm{mL}$ ) $125 \mu \mathrm{g}$ each were given intramuscularly (IM) at 12 days interval. Draining of uterine fluids was observed 3 days after first dose of Vetmate ${ }^{\circledR}$ injection and animal recovered uneventfully.

\section{Introduction}

Hydrometra is one of the important causes of anoestrus in dairy goats. The incidence of hydrometra varies from 3 to $5 \%(7.69 \%)$ and often seen in herds of dairy goats. It is a major cause of infertility in goats (Souza et al., 2013). It occurs in goats when the coupus luteum (CL) persists in the absence of a viable foetus with constantly elevated plasma progesterone levels (>3 ng/mL) (Hesselink, 1993). This persistent CL induces the blockage of the hypothalamo-hypophyseal axis resulting in cessation of reproductive activity (Kornalijnslijper et al., 1997). The condition is characterized by variable degrees of abdominal distension due to the accumulation of sterile secretions within the uterine lumen i.e. hydrometra (Pieterse and Taverne, 1986) accompanied by a progressive mammary development. A profuse discharge of 'watery' fluid occurs on termination of the condition, colloquially referred to as "cloudburst" (Smith, 2001).

\section{History and clinical examination}

A two and half years old primiparous non- 
descript doe was presented to Referral veterinary polyclinic (Veterinary Gynaecology and Obstetrics section) of the Indian Veterinary Research Institute, Izatnagar with distended abdomen along with the history of breeding five months back (Fig.1).

Clinical examination revealed moderate abdominal distension and teat engorgement. Animal was healthy and no abnormal genital discharge was seen. No fetal parts were felt on ventral abdominal palpation and on pervaginal examination.

\section{Trans-abdominal}

ultrasonographic examination using a $5.0 \mathrm{MHz}$ transducer was performed with the goat in left lateral recumbency. B- mode ultrasonographic examination revealed highly distended uterine horns with large anechoic areas as circumscribed cross-sectioned sacculations.

The anechoic fluid compartments were separated by thin hyperechoic trabeculae (Fig.2) probably due to coiling of the uterine horns. Further, absence of embryonic/fetal and maternal caruncular structures confirmed it to be non-gravid uterus filled with fluid. Based on the observation of ultrasonographic examination, the condition was diagnosed as hydrometra.

\section{Results and Discussion}

The goat was administered $125 \mu \mathrm{g}$ of Vetmate $^{\circledR}$ Inj. (Cloprostenol- Synthetic Prostaglandin $\mathrm{F}_{2} \alpha 250 \mu \mathrm{g} / \mathrm{mL}$ ) IM on the day of presentation. On day $3^{\text {rd }}$ post treatment, history of clear vaginal discharge and reduction in abdominal distension was reported. Second injection of Vetmate ${ }^{\circledR}$ at the same dose was given after 12 days. Following the second dose, the animal displayed behavioural signs of estrus on third day. The result of the present study is in agreement with Pieterse and Taverne (1986) who reported that a single administration of $\mathrm{PGF}_{2} \alpha$ was not sufficient to completely evacuate the fluid present in the uterus and to reduce the recurrence of the condition. Moreover, Hesselink (1993) and Simon et al. (2010) have reported that the double injection regime within an interval of 12 days significantly increased the reproductive performance in goats. Taverne et al. (1995) inferred that accumulation of fluid is the result, rather than the cause of the persistence of the corpus luteum and that the disturbances in either the luteotropic or luteolytic mechanism during the ovarian cycle play an important role in the etiology of this condition.

Fig.1. Goat presented at polyclinic

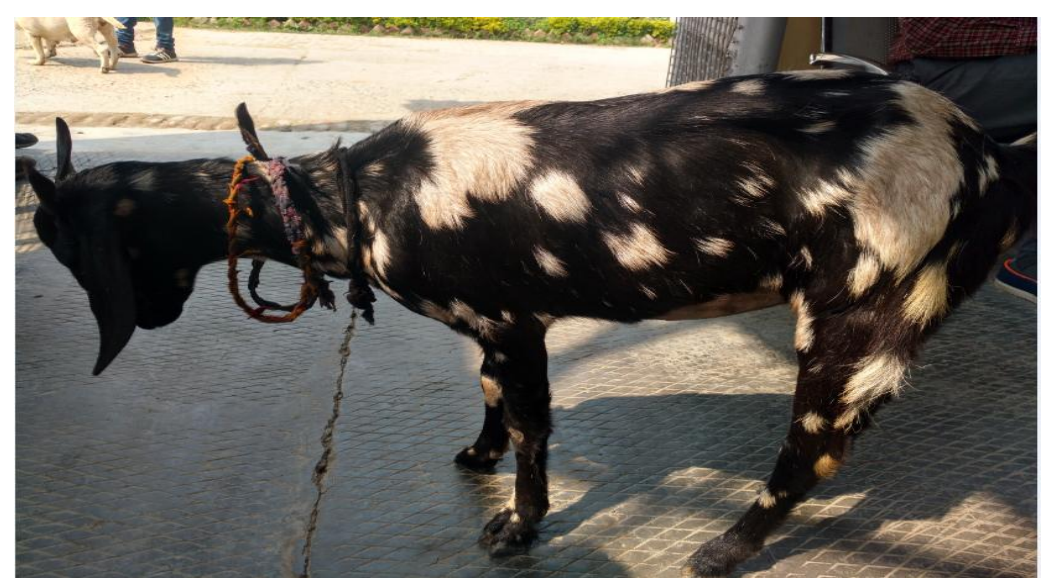


Fig.2 B-mode ultrasonographic image showing anechoic fluid compartments in the uterus separated by hyperechoic trabeculae

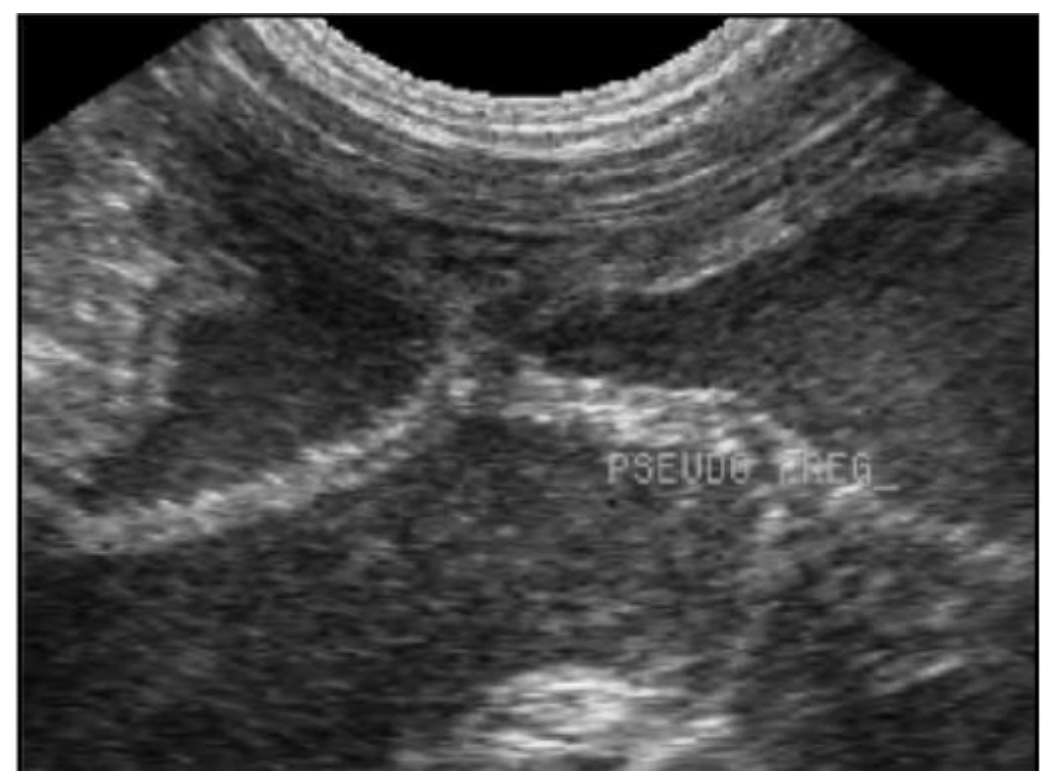

In conclusion, hydrometa might not be considered as a disease as it is just a condition that mimics normal and natural pregnancy state of animal without affecting the general health status of the animal. However, because of its economic impact associated with lack of production of viable kids and milk, early diagnosis and treatment of this condition in does is very important for quick return to normal reproductive cycle.

\section{Acknowledgement}

The corresponding author would like to thank Director, Indian Veterinary Research Institute for providing financial assistance in the form of institutional Fellowship.

\section{References}

Hesselink, J.W., Taverne, M.A.M., Bevers, M.M. and Van Oord H.A. 1995. Serum prolactin concentrations in pseudopregnant and normal reproducing goats. Vet. Rec. 137: 166168.

Kornalijnslijper, J.E., Kemp, B., Bevers, M.M., Van Oord H.A. and Taverne, M.A.M.1997. Induction of hydrometra in goats by means of active immunization against $\mathrm{PGF}_{2} \alpha$. Anim. Reprod. Sci. 46: 109-122.

Pieterse, M. and Taverne, M. 1986. Hydrometra in goats: Diagnosis with real-time ultrasound and treatment with prostaglandin or oxytocin. Theriogenology.26: 813-821.

Simon, S., Vergis, J., Krishnan, G.S., Arun, A., Vishnuraj, M.R., Rekha, V. and Renjith, R. 2010. Pseudopregnancy in goat. J. indian Vet. Assoc. 8: 17-19.

Smith, K.C. 2001. Infertility in the ewe and doe (Female Goat). In: Arthur's Veterinary Reproduction and Obstetrics. D.E. Noakes, T.J. Parkinson and G.C.W. England (Eds.), 8th Edition, W.B. Saunders Company, Philadelphia, pp. 570-571. 
Souza, J., Maia, A., Brandao, F., Vilela, C., Oba, E., Bruschi, J. and Fonseca, J. 2013. Hormonal treatment of dairy goats affected by hydrometra

Taverne, M.A.M., Hesselink, J.W., Bevers, M.M., van Oord, H.A. and Kornalijnslijer, J.E. 1995. Aetiology associated or not with ovarian follicular cyst. Small Rumin Res. 111: 104-109.

and endocrinology of pseudopregnancy in the goat. Reprod. Dom. Anim. 30: 228-230.

\section{How to cite this article:}

Balamurugan, B., Abhishek Kumar, M. Ramamoorthy and Ajaz Ali. 2018. Successful Therapeutic Management of Hydrometra in a Doe- A Case Report. Int.J.Curr.Microbiol.App.Sci. 7(07): 2044-2047. doi: https://doi.org/10.20546/ijcmas.2018.707.241 